\title{
A rare case of SDHB mutation in a male individual with pituitary adenoma, and paraganglioma/phaeochromocytoma syndrome.
}

\section{Valentinos Kounnis, Saeed ElMuhtadi, Aparna Pal, Mike Tadman, Bahram Jafar-Mohammadi}

The Oxford Center for Diabetes, Endocrinology and Metabolism, University of Oxford, UK

\section{Introduction}

Herein we provide clinical, biochemical, histological and radiological evidence of a rare case of a male patient who was diagnosed with pituitary macroadenoma (prolactinoma), phaeochromocytoma and a lung typical-carcinoid tumour on a background of SDH gene mutation encoding the succinate dehydrogenase enzyme.

\begin{tabular}{|c|c|c|}
\hline Test & Result & Reference Range \\
\hline Prolactin & 9723 & 45-375 mU/L \\
\hline Testosterone & 7.5 & $8.4-28.7 \mathrm{nmol} / \mathrm{L}$ \\
\hline LH & 0.5 & $1.5-9.3 \mathrm{IU} / \mathrm{L}$ \\
\hline FSH & 2.0 & $2.0-20 \mathrm{IU} / \mathrm{L}$ \\
\hline FT4 & 1.99 & $0.35-5.5 \mathrm{mU} / \mathrm{L}$ \\
\hline IGF1 & 14.4 & $10.5-20 \mathrm{pmol} / \mathrm{L}$ \\
\hline SST & 535 -> 766 & \\
\hline
\end{tabular}

Initial Biochemistry

\begin{tabular}{|c|c|c|}
\hline Test & Result & Reference Range \\
\hline Normetadrenaline & 3.88 & $0-3.45 \mu \mathrm{mol} / 24 \mathrm{~h}$ \\
\hline Metadrenaline & 1.12 & 0 - $1.4 \mu \mathrm{mol} / 24 \mathrm{~h}$ \\
\hline 3-Methoxytyramine & 4.01 & $0-2.55 \mu \mathrm{mol} / 24 \mathrm{~h}$ \\
\hline
\end{tabular}

Urinary Metanephrines
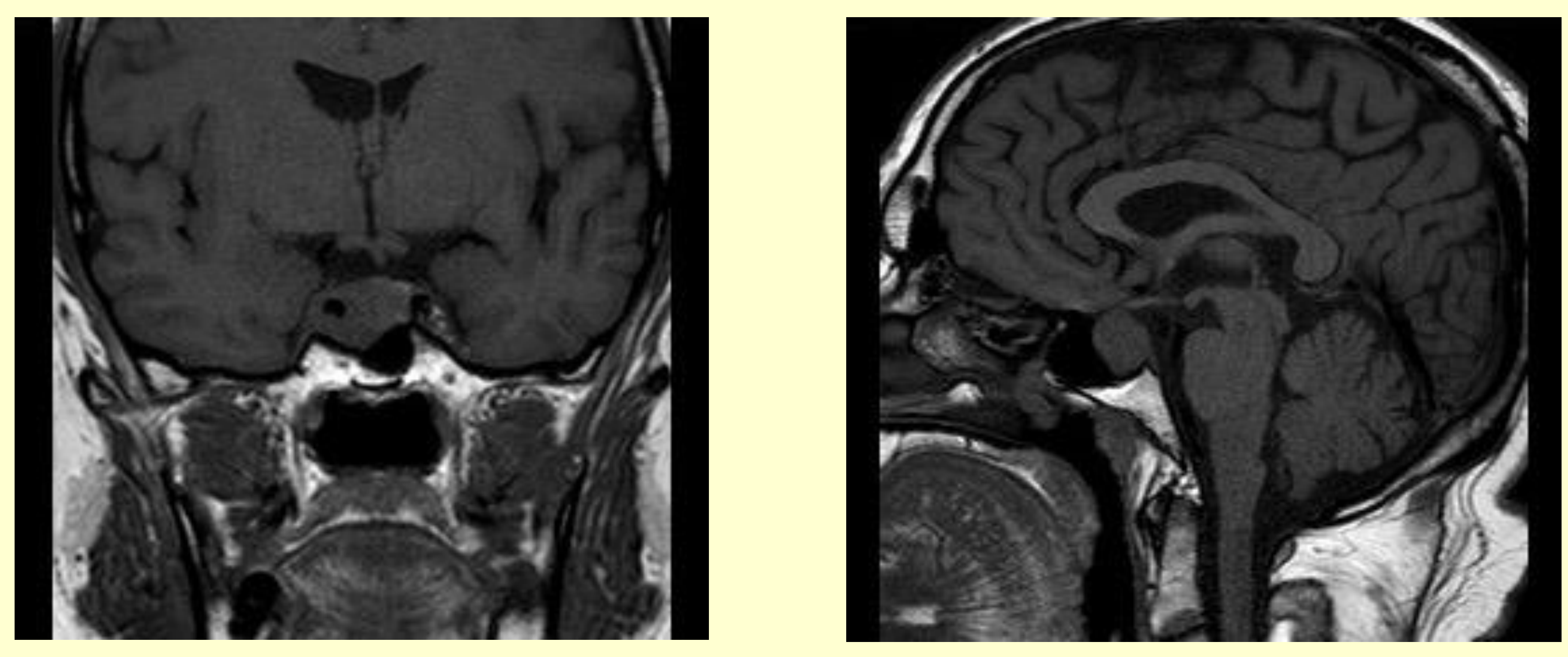

Initial Imaging

\section{Presentation of Case}

A 42 year old male individual, was initially diagnosed with a pituitary macroadenoma (prolactinoma) after complaining of persisting severe headaches, for which cabergoline treatment had been initiated.

His positive paternal history of phaeochromocytoma, led to further genetic screening which revealed a c.600>A, p.(Trp200*) mutation in the SDHB gene and further biochemical and imaging studies confirmed the presence of a phaeochromocytoma, which was surgically excised.

Following a random hospital visit, a plain chest radiograph raised concerns over a right lower lobe mass which ultimately led to advanced imaging studies with CT and PET, confirming the presence of a neoplastic lesion with no evidence of lymphadenopathy of other evidence of metastatic disease.

A subsequent lobectomy and Histopathological analysis (positive for chromogranin and synaptophysin) confirmed the diagnosis of a typical carcinoid tumour (stage pT1b NO Mx).
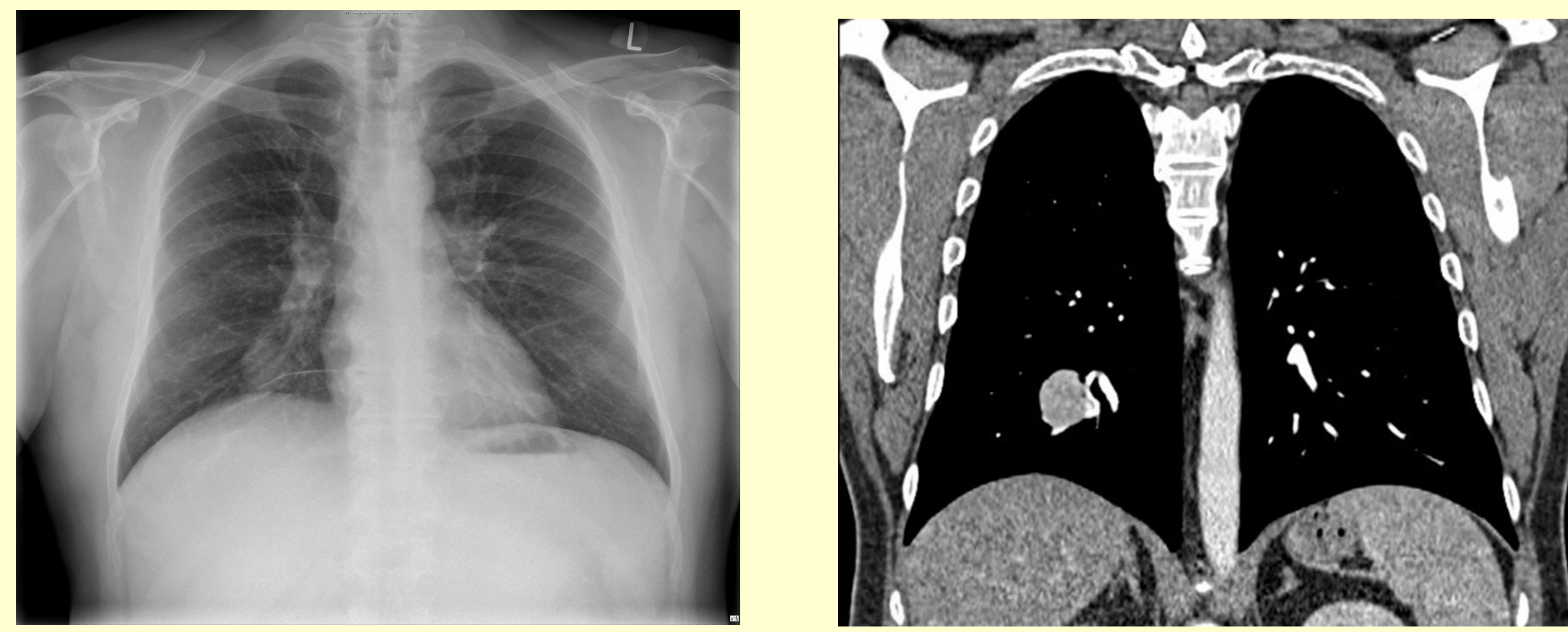

Two months post initial presentation
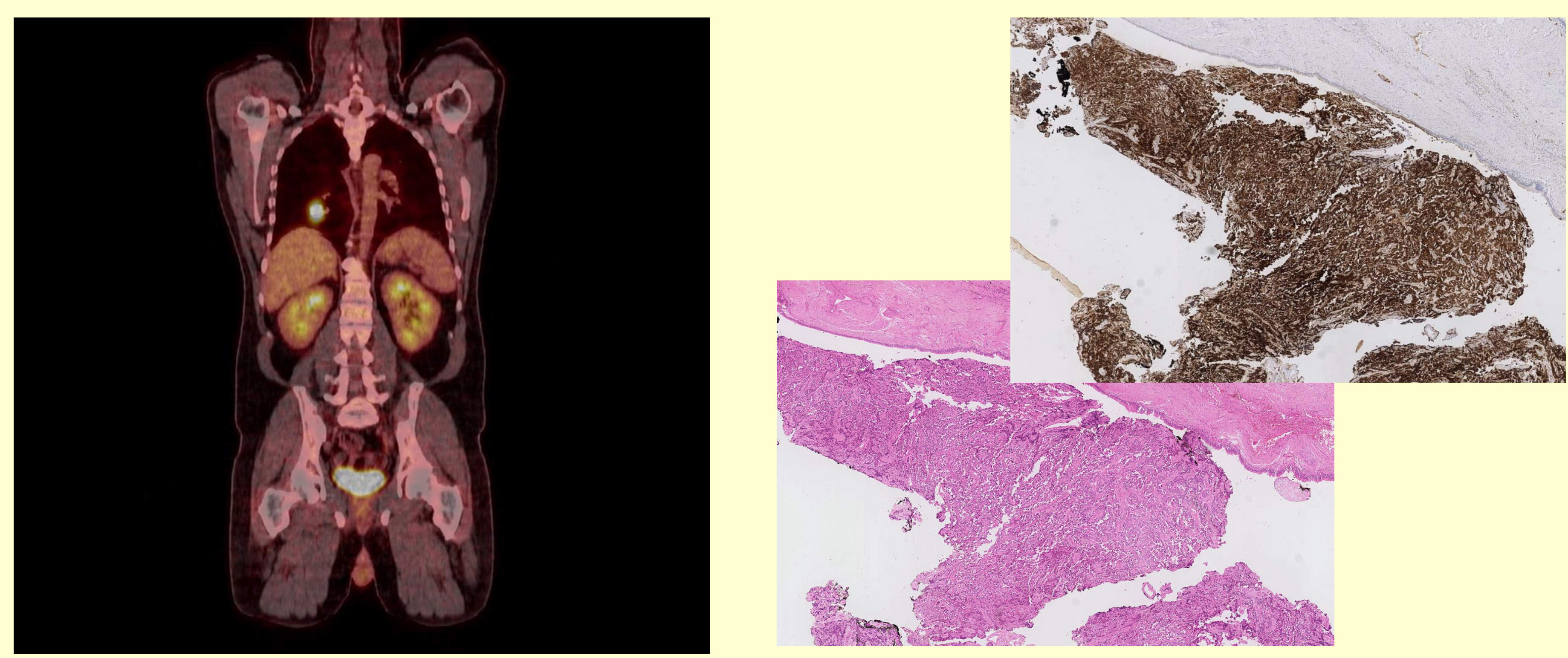

\section{Discussion}

The role of mutations in the genes encoding the succinate dehydrogenase $(\mathrm{SDH})$ subunits, in tumorigenesis has been described previously and especially the predisposition to the development of the hereditary paraganglioma/phaeochromocytoma syndrome (HPGL/PCC).

To our knowledge this may be the first reported case of a lung neuroendocrine tumour, phaeochromocytoma and pituitary macroadenoma on the background of a mutation in the SDHB gene.
PET scan and Histology sample/ +ve for Chromogranin

\footnotetext{
1. Bardella, C., P.J. Pollard, and I. Tomlinson, SDH mutations in cancer. Biochim Biophys Acta, 2011. 1807(11): p.1432-43

2. Couldwell, W.T. and L. Cannon-Albright, A heritable predisposition to pituitary tumors Pituitary, 2010. 13(2): p. 130-7.

3. Efstathiadou, Z.A., et al., Unusual case of Cowden-like syndrome, neck paraganglioma, and pituitary adenoma. Head Neck, 2014. 36(1): p.E12-6.

4. Lefebvre, M. and W.D. Foulkes, Pheochromocytoma and paraganglioma syndromes: genetics and management update. Curr Oncol, 2014. 21(1): p.e8-e17.

5. Zhan, X., X. Wang, and T. Cheng, Human Pituitary Adenoma Proteomics: New Progresses and Perspectives. Front Endocrinol (Lausanne), 2016. 7: p.54.
} 